\title{
DNA microarray data integration by ortholog gene analysis reveals potential molecular mechanisms of estrogen-dependent growth of human uterine fibroids
}

\author{
Tao Wei ${ }^{1}$, Andrew G Geiser ${ }^{2}$, Hui-Rong Qian ${ }^{3}$, Chen Su${ }^{1}$, Leah M Helvering2 \\ Nalini H Kulkarini ${ }^{1}$, Jianyong Shou ${ }^{1}$, Mathias $\mathrm{N}^{\prime} \mathrm{Cho}^{1}{ }^{1}$, Henry U Bryant ${ }^{2}$ and \\ Jude E Onyia*1
}

Address: ${ }^{1}$ Integrative Biology, Lilly Research Laboratories, Greenfield, Indiana 46140, USA, ${ }^{2}$ Bone and Inflammation, Lilly Research Laboratories, Indianapolis, Indiana 46285, USA and ${ }^{3}$ Discovery Statistics, Lilly Research Laboratories, Indianapolis, Indiana 46285, USA

Email: Tao Wei - weita@lilly.com; Andrew G Geiser - ageiser@lilly.com; Hui-Rong Qian - qianhu@lilly.com; Chen Su - chen_su@lilly.com; Leah M Helvering - l.helvering@lilly.com; Nalini H Kulkarini - kulkarninh@lilly.com; Jianyong Shou - shou@lilly.com; Mathias N'Cho - n_mathias@lilly.com; Henry U Bryant - hub30@lilly.com; Jude E Onyia* - jeo@lilly.com

* Corresponding author

\section{Published: 2 April 2007}

BMC Women's Health 2007, 7:5 doi:10.1186/1472-6874-7-5
Received: 7 November 2006

Accepted: 2 April 2007

This article is available from: http://www.biomedcentral.com/1472-6874/7/5

(c) 2007 Wei et al; licensee BioMed Central Ltd.

This is an Open Access article distributed under the terms of the Creative Commons Attribution License (http://creativecommons.org/licenses/by/2.0), which permits unrestricted use, distribution, and reproduction in any medium, provided the original work is properly cited.

\begin{abstract}
Background: Uterine fibroids or leiomyoma are a common benign smooth muscle tumor. The tumor growth is well known to be estrogen-dependent. However, the molecular mechanisms of its estrogen-dependency is not well understood.

Methods: Differentially expressed genes in human uterine fibroids were either retrieved from published papers or from our own statistical analysis of downloaded array data. Probes for the same genes on different Affymetrix chips were mapped based on probe comparison information provided by Affymetrix. Genes identified by two or three array studies were submitted for ortholog analysis. Human and rat ortholog genes were identified by using ortholog gene databases, HomoloGene and TOGA and were confirmed by synteny analysis with MultiContigView tool in the Ensembl genome browser.
\end{abstract}

Results: By integrated analysis of three recently published DNA microarray studies with human tissue, thirty-eight genes were found to be differentially expressed in the same direction in fibroid compared to adjacent uterine myometrium by at least two research groups. Among these genes, twelve with rat orthologs were identified as estrogen-regulated from our array study investigating uterine expression in ovariectomized rats treated with estrogen. Functional and pathway analyses of the twelve genes suggested multiple molecular mechanisms for estrogen-dependent cell survival and tumor growth. Firstly, estrogen increased expression of the anti-apoptotic PCP4 gene and suppressed the expression of growth inhibitory receptors PTGER3 and TGFBR2. Secondly, estrogen may antagonize PPAR $\gamma$ signaling, thought to inhibit fibroid growth and survival, at two points in the PPAR pathway: I) through increased ANXAI gene expression which can inhibit phospholipase $\mathrm{A} 2$ activity and in turn decrease arachidonic acid synthesis, and 2) by decreasing L-PGDS expression which would reduce synthesis of PGJ2, an endogenous ligand for PPAR $\gamma$. Lastly, estrogen affects retinoic acid (RA) synthesis and mobilization by regulating expression of CRABP2 and ALDHIAI. RA has been shown to play a significant role in the development of uterine fibroids in an animal model.

Conclusion: Integrated analysis of multiple array datasets revealed twelve human and rat ortholog genes that were differentially expressed in human uterine fibroids and transcriptionally responsive to estrogen in the rat uterus. 
Functional and pathway analysis of these genes suggest multiple potential molecular mechanisms for the poorly understood estrogen-dependent growth of uterine fibroids. Fully understanding the exact molecular interactions among these gene products requires further study to validate their roles in uterine fibroids. This work provides new avenues of study which could influence the future direction of therapeutic intervention for the disease.

\section{Background}

Leiomyoma or uterine fibroids are the most common benign tumor, occurring in approximately $60 \%$ of women during their lifetime[1]. In spite of its generally benign nature, uterine fibroids cause an array of substantial health problems in some women such as pressure or pain, excessive uterine bleeding and problems related to pregnancy [2]. As a consequence, uterine fibroids account for approximately one-third of all hysterectomies in the United States or about 200,000 hysterectomies per year [3]

Although the etiology of the disease is largely unknown, it is clear that growth of uterine fibroids depends on the ovarian hormones estrogen and progesterone [2]. This hormonal dependency is supported by the following observations. Uterine fibroids are observed only after menarche, increase in size during pregnancy, and frequently regress after menopause (reviewed in [2]). The tumors can be induced to regress by surgical ovariectomy or by treatment with GnRH agonists which induce a hypoestrogenic state[4]. Tissue estrogen concentrations are elevated in uterine fibroids compared to myometrium, which may result from increased aromatase activity [5]. Estrogen produces diverse biological effects mediated by estrogen receptors (ER). When bound to estrogen, the ER modulates the transcriptional activity of target genes [6,7]. Evidence shows that one effect of estrogen is to increase the levels of both estrogen receptor (ER) and progesterone receptor $(\mathrm{PR})$ [2]. It has been recently demonstrated that estrogen can stabilize ER mRNA, increasing the level of cellular ER protein [8].

While it is well established that growth of uterine fibroids depends on estrogen, molecular mechanisms of such estrogen dependency are largely unknown. Numerous studies have indicated that estrogen may mediate fibroid growth through the mitogenic effects of growth factors such as transforming growth factor- $\beta$ and basic fibroblast growth factor (reviewed in [2]). There have been a few recent studies addressing molecular mechanisms of functional interaction between estrogen signaling and growth factor-mediated signaling in the pathogenesis of uterine fibroids. Work by Hayashi et al [9] in estrogen-dependent cancers provides an example where the constitutively activated MAPK signaling pathway in endometrial cancer cells might enhance the transcriptional activity of ER $\alpha$ via phosphorylation of its AF-1 domain. Wnt signaling was recently implicated in the pathogenesis of uterine fibroids where the secreted frizzled related protein 1 (sFRP1) mRNA [10] was found to be significantly elevated in the tumor, and regulated by estrogen treatment. It was shown that sFRP1 contributes to fibroid growth through an antiapoptotic effect.

A recent report has shown that PPAR $\gamma$ activation by its ligand (i.e., prostaglandin J2) in uterine fibroids is growth inhibitory and mediated at least in part by negative crosstalk between ER and PPAR $\gamma$ signaling pathways [11]. However, the exact molecular mechanisms of how such interaction occurs between the two nuclear receptor signaling pathways remain to be answered. Elevated levels of PPAR $\gamma$, retinoid $\times$ receptor alpha $(\mathrm{RXR} \alpha)$, and all-trans retinoic acid were observed in human uterine fibroids, and retinoids in combination with estrogen was shown to induce development of uterine fibroids in a guinea pig model [12].

DNA microarray technology allows simultaneous interrogation of tens of thousands of genes [13]. Several studies have applied the technology to identify genes that were differentially expressed in human uterine fibroids compared to adjacent normal myometrium [14]. The technology has also been applied to identify estrogen-regulated genes in the adult rat uterus [15]. To understand the molecular interactions involved in estrogenic support of uterine fibroid growth, we integrated results from the above DNA microarray studies using ortholog analysis. Orthologous genes are related by direct evolutionary descent and should play similar developmental or physiological roles [16]. This study identified twelve human and rat orthologous genes that were differentially expressed in human uterine fibroids and estrogen-regulated in the adult rat uterus, and describes their possible cellular and physiological roles in estrogen-dependent tumor growth.

\section{Methods \\ Published DNA microarray data sets}

Table 1 lists four published DNA microarray data sets used in this work. Briefly, researchers [14,17,18] profiled biopsy samples taken from uterine fibroids and myometrial tissues of each patient (paired experimental design) to identify differentially expressed statistically significant $(P<0.05)$ genes. Helvering et al [15] profiled genes expressed in the uteri of adult ovariectomized rats treated 
with estrogen for 24 hours or for five weeks. Estrogen regulated genes were identified as genes with false discovery error rates $<0.05$ [19] and showed an opposite direction of change when comparing genes differentially expressed between ovariectomized and sham controls versus genes differentially expressed between ovariectomized controls with ovariectomized animals treated with estrogen (E) at either time points

\section{Identification of human and rat ortholog genes that are estrogen responsive and differentially expressed in uterine fibroids}

Figure 1 shows the procedure that was employed to identify human and rat ortholog genes that were differentially expressed in human uterine fibroids and estrogen-regulated in rat uterus. In the first step two gene lists were constructed. The first gene list included human genes differentially expressed in human uterine fibroids identified by three independent groups [14], which were retrieved from either published papers or from the Gene Expression Omnibus database [20]. Since the three studies employed distinct Affymetrix chip types the information of chip comparison was retrieved from the NetAffx web site[21] to map genes from one chip type to another. Genes commonly identified by two or three groups were regarded as true differentially expressed genes and thus selected for ortholog analysis. The second gene list included estrogen-responsive genes in the rat uterus which were obtained from the work by Helvering et al[15]. The second step was to identify putative ortholog genes from these two gene lists. Two major eukaryotic ortholog gene databases, namely HomoloGene [22] and TOGA [23], were queried for each of the tumor differentially expressed genes to identify putative rat orthologs and LocusLink numbers were then used to retrieve Affymetrix probe sets on rat RG-U34A chips. These probe sets were next compared with probe sets identified by Helvering et al [15] to find putative human rat orthologs. Finally, an in silico confirmation of expression and ortholog gene identity was performed by examining each Affymetrix probe set for its specificity to measure expression using the BLAT program [24] which aligned Affymetrix's target sequences against both human and rat genomes. Genes were considered if their Affymetrix target sequences mapped to only one major genome location. To confirm orthologous genes identified above, each gene was queried in the Ensembl genome browser [25] and gene structure, chromosomal location and synteny information were visually examined with Ensembl MultiContigView [25]. Lastly, functional and pathway analysis of ortholog genes were conducted to understand cellular and physiological implications.

To calculate functional distribution of the human genes differentially expressed in uterine fibroids, a web tool FatiGO developed by [26] was used according to its online instruction.

\section{Results}

\section{Genes differentially expressed in human uterine fibroids}

Differential expression of genes between human uterine fibroids and adjacent normal myometrium were identified by three independent research groups as shown in Table 1 . The number of genes identified was significantly different among the three studies. All three studies used matched fibroid and myometrial tissue. However, the studies differed in the following aspects. First, the ethnic background of the patients was very different. For example, in Wang's experiment the patients were largely African-American whereas in the Tsibris et al study the patients were mainly of Northern European descent. It is well known that uterine fibroids are much more prevalent in African-American women than in Caucasian women (reviewed in [2]). Secondly, tissues were sampled from patients at different ovarian phases. The number of genes identified was significantly greater in the Hoffman and Tsibris studies where samples were taken from both the follicular and luteal phases compared to the Wang study where the authors sampled tissues from the follicular phase only. Thirdly, different DNA chips were used (Table 1). These differed in the number of genes arrayed on each chip, probe pairs for a given probe set, and probe pairs for the same gene that might be taken from different metrix target sequences. By using information on chip comparisons provided by NetAffx[21], we identified thirty-eight genes (Table 2) that were commonly reported to be significantly changed in the same direction in two or three studies. Functional distribution within gene ontology space

Table I: Published DNA microarray experiments

\begin{tabular}{|c|c|c|c|c|c|}
\hline Species & Tissue & Chip Used & Sample Size & No of Genes Identified & References \\
\hline \multirow[t]{3}{*}{ Human } & Uterine fibroids and normal myometrium & HG-U95A HuGeneFL & 9 pairs & $106^{a}$ & [14] \\
\hline & & HuGeneFL & 7 pairs & 68 & {$[17]$} \\
\hline & & HG-UI33A & 5 pairs & $226^{b}$ & [18] \\
\hline Rat & Uteri from vehicle and estrogen treated animals & RG-U34A & 5 rats per treatment, 2 chip for each animal & $3927^{c}$ & {$[15]$} \\
\hline
\end{tabular}

a the authors reported 145 genes but only 106 accessions could be retrieved from the paper.

$\mathrm{b}$ represents the number of the Affymetrix probe sets.

c the probe sets were significant with false discovery rate $<0.05$ by either one - day or five - week estrogen treatment of ovariectomized rats. 


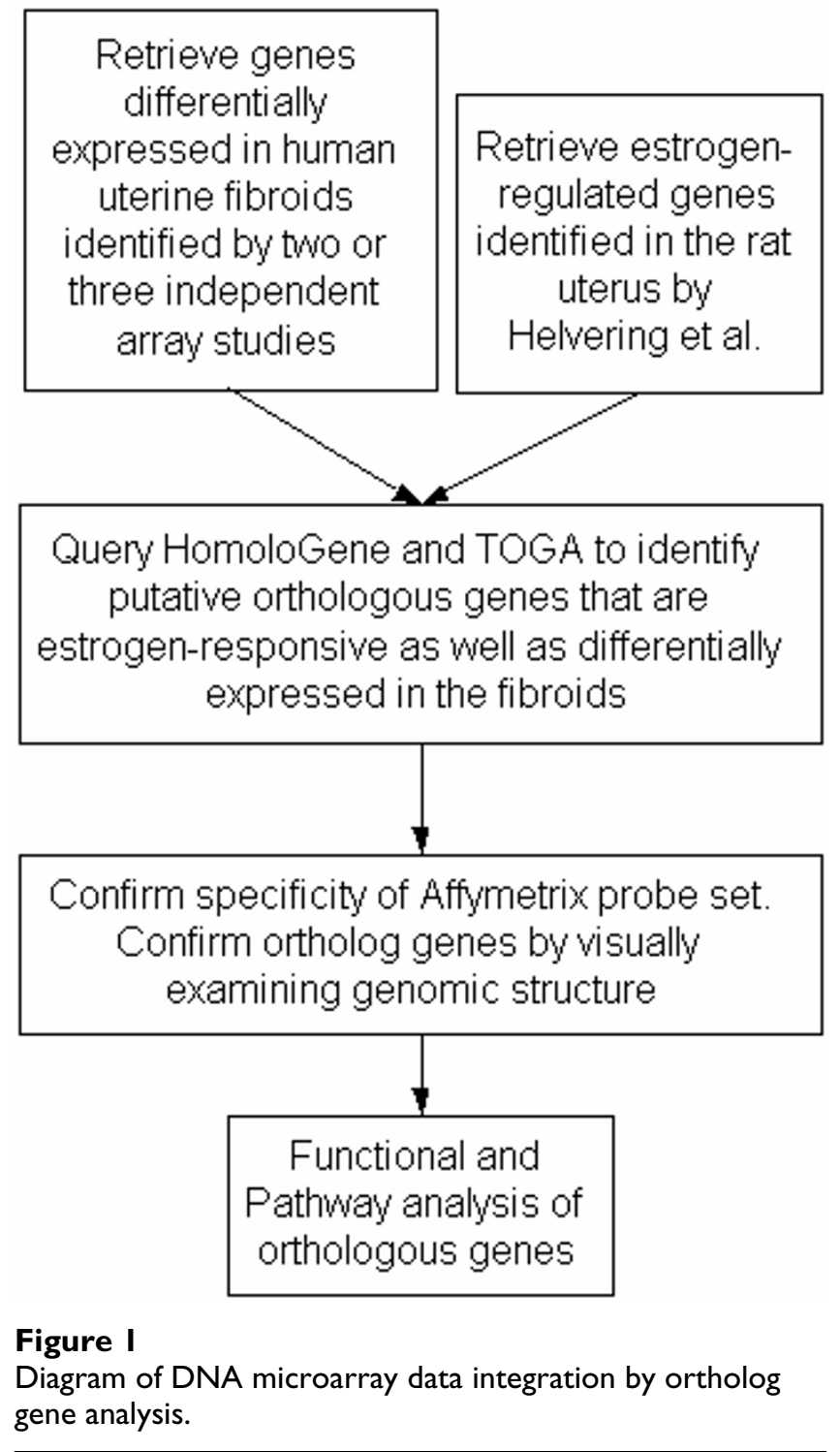

(Figure 2) was calculated by the FatiGO program [26]. The top ranked functional categories include transcription, regulation of nucleotide metabolism, cell surface receptor-linked signal transduction, protein metabolism, cell organization and biogenesis, cell proliferation, intracellular signaling cascade, defense response and transport.

\section{Estrogen-regulated genes in the uterus of ovariectomized adult rats}

Helvering et al [15] evaluated short and long-term effects of ovariectomy and treatment with estrogen on expression changes in the uterus of ovariectomized rats. They found that ovariectomy induced dramatic gene expression changes in the uterus both at 13 days and at 5 weeks post surgery with 1930 or 2908 Affymetrix probes changed, respectively. Treatment of ovariectomized rats with 0.1 $\mathrm{mg} / \mathrm{kg} /$ day $17-\beta$ ethinyl estradiol also induced significant changes with 2389 probes altered following 1-day of treatment and 2990 probes following 5-week treatment. In total, there were 3927 Affymetrix probe sets that were changed by ovariectomy and then altered in the opposite direction by estrogen treatment of ovariectomized rats at two time points.

\section{Identification of orthologous genes differentially expressed in human uterine fibroids and regulated by estrogen in the rat uterus}

Each of the thirty-eight genes differentially expressed in human uterine fibroids was queried against the HomoloGene and TOGA databases for rat ortholog genes, among which twelve genes were found to be responsive to estrogen treatment in the rat uterus. Table 3 shows relative changes of expression of the twelve human and rat orthologs obtained from the original study. All twelve genes showed high and consistent transcriptional changes in uterine fibroids across two or three independent studies and also responded to ovariectomy and estrogen treatment in reversed manner consistently at both time points.

To confirm that the Affymetrix probe sets were indeed specific for each gene we confirmed their alignment with the human and rat genomes using the BLAT tool [24] at UCSC [27]. Except for Affymetrix target sequence of rat gene C1S which produced two major alignments in the q42 cytoband of rat chromosome 4, one spanning 160981068 to 160993069 with $98.6 \%$ identities and the other spanning 160609849 to 160612122 with $75.7 \%$ identities, Affymetrix target sequences of all the other twelve genes generated one major alignment to the expected gene in the human and rat genomes. For example, the rat target sequence for the rat L-PGDS gene had a single, major alignment with the L-PGDS gene on chromosome 3 in the rat genome and the human target sequence generated a single alignment with L-PGDS gene on chromosome 9 in the human genome. Thus we believe that expression signals of the twelve human and rat orthologs, except for the gene C1S, obtained by Affymetrix chips used in these studies could accurately measure mRNA abundance of the twelve genes in the human and rat samples.

To demonstrate that the twelve genes are genuinely human and rat ortholog genes, each of them was queried in the UCSF and Ensembl genome browsers to visually examine the local genome structure and compare them between the two species. Figure 3 shows the genome structure of ALDH1A1 and ANXA1 as an example. Interestingly, ALDH1A1 and ANXA1 genes map to a common chromosomal region in both species and the genomic structures are well conserved among human, mouse and rat. This relationship, regarded as a synteny, provides strong evidence for orthologship of the two genes among human, rat and mouse. Similarly, the rest of the ten genes 


\begin{tabular}{l|c} 
transcription & $21.88 \%$ \\
regulation of nucleobase, nucleoside, nucleotide and nuclei... & $18.75 \%$ \\
cell surface receptor linked signal transduction & $15.62 \%$ \\
protein netabolisn & $15.62 \%$ \\
cell organization and biogenesis & $15.62 \%$ \\
cell proliferation & $12.50 \%$ \\
intracellular signaling cascade & $9.38 \%$ \\
defense response & $9.38 \%$ \\
transport & $9.38 \%$ \\
response to pest, pathogen or parasite & $9.38 \%$ \\
nacronolecule catabolisn & $9.38 \%$ \\
cell grouth & $6.25 \%$ \\
lipid biosynthesis & $6.25 \%$ \\
histogenesis & $6.25 \%$ \\
regulation of cell size & $6.25 \%$ \\
nacronolecule biosynthesis & $6.25 \%$ \\
response to nounding & $6.25 \%$ \\
detection of external stinulus & $6.25 \%$ \\
nusculoskeletal novenent & $6.25 \%$ \\
regulation of cell grouth & $6.25 \%$ \\
sensory perception & $6.25 \%$ \\
\hline
\end{tabular}

Figure 2

Functional distribution of thirty-eight genes differentially expressed in human uterine fibroids. The analysis was done using a web tool FatiGO developed by Al-Shahrour et al. [26]. Since some genes are involved in multiple biological processes the sum of percentage is more than 100.

are also located in their respective syntenic chromosomal regions in two species (data not shown).

A literature search was conducted for each of the twelve genes to determine if others have previously identified these genes to be directly regulated by estrogen (Table 3). Cellular retinoic acid binding protein 2 (CRABP2) and aldehyde dehydrogenase 1 A1 (ALDH1A1) were previously shown to directly respond to estrogen in the rat uterus $[28,29]$ in the same fashion as observed by Helvering using DNA microarray. Lipocalin-type prostaglandin D synthase (L-PGDS) was reported to respond to estrogen in a more complicated fashion depending on the tissues/ organs. For example, L-PGDS transcription was induced in the medial basal hypothalamus and repressed in the preoptic area in female adult mice by estrogen [30,31]. Transcription of L-PGDS was also induced in mouse heart in vivo specifically by estrogen receptor beta via a functional estrogen-responsive element in the L-PGDS promoter [32]. Castro-Caldas et al [33] demonstrated that estrogen induced de novo expression of annexin A1 (ANXA1) and stimulated its secretion in the human CCRF-CEM acute lymphoblastic leukemia cell line apparently via a mechanism independent of the intracellular estrogen receptor. Consistent with this result we couldn't find any putative estrogen responsive element in its $5 \mathrm{~kb}$ promoter sequence. Expression of calcitonin receptor-like receptor (CALCRL) was inhibited by estrogen in the rat uterus [34] and placenta [35]. Nuclear receptor subfamily 4 , group A, member 1 (NR4A1) whose human promoter 
Table 2: Genes with differential expression in human uterine fibroids identified by two or three groups of researchers.

\begin{tabular}{|c|c|c|c|c|c|}
\hline Accession ${ }^{\mathrm{a}}$ & Symbolb & Gene Descritpion ${ }^{b}$ & $\mathrm{H}^{\mathrm{c}}$ & $\mathrm{Tc}^{\mathrm{c}}$ & Wc \\
\hline NM 007168 & $\mathrm{ABCA} 8$ & ATP-binding cassette, sub-family $A(A B C I)$, member 8 & -2.5 & -5.7 & \\
\hline NM 006720 & ABLIMI & actin binding LIM protein I & -3.3 & -4.28 & \\
\hline NM 000689 & ALDHIAI & aldehyde dehydrogenase I family, member AI & -3.5 & -7.98 & -4 \\
\hline NM 000700 & ANXAI & annexin $\mathrm{Al}$ & -4.1 & -4.32 & \\
\hline NM 001674 & ATF3 & activating transcription factor 3 & -8.8 & -6.04 & \\
\hline MI8767 & CIS & complement component I, s subcomponent & -2.5 & & -3.2 \\
\hline NM 004772 & C5orfl 3 & chromosome 5 open reading frame 13 & 2.45 & 2.81 & \\
\hline NM 001218 & CAI2 & carbonic anhydrase XII & 3.81 & 4.8 & \\
\hline $\mathrm{U} 17473$ & CALCRL & calcitonin receptor-like receptor & -2.1 & & -1.7 \\
\hline NM 001870 & CPA3 & carboxypeptidase A3 (mast cell) & -2.1 & -8.18 & \\
\hline NM 001878 & CRABP2 & cellular retinoic acid binding protein 2 & 3.05 & 5.12 & 2.6 \\
\hline AF003114 & CYR6I & cysteine-rich, angiogenic inducer, 61 & -5.8 & -5.3 & \\
\hline Al826799 & EFEMPI & EGF-containing fibulin-like extracellular matrix protein I & -4.1 & -4.51 & -5 \\
\hline BC004490 & FOS & $\mathrm{v}$-fos FBJ murine osteosarcoma viral oncogene homolog & -9.5 & -8.17 & \\
\hline NM 007003 & GAGECI & G antigen, family $\mathrm{C}, \mathrm{I}$ & 2.98 & 40.7 & \\
\hline NM 000826 & GRIA2 & glutamate receptor, ionotropic, AMPA 2 & 7.48 & 38.8 & 4.9 \\
\hline 03242 & IGF2 & insulin-like growth factor 2 (somatomedin A) & & 16.8 & 2.6 \\
\hline NM 002178 & IGFBP6 & insulin-like growth factor binding protein 6 & -4.5 & -5.26 & \\
\hline NM 004522 & KIF5C & kinesin family member $5 \mathrm{C}$ & 2.12 & 9.02 & \\
\hline AL021977 & MAFF & v-maf musculoaponeurotic fibrosarcoma oncogene homolog F (avian) & -6.8 & -3.38 & \\
\hline NM 005923 & MAP3K5 & mitogen-activated protein kinase kinase kinase 5 & -2.1 & -4.13 & -3 \\
\hline NM 002402 & MEST & mesoderm specific transcript homolog (mouse) & 3.87 & 11.6 & 2.4 \\
\hline NM 002135 & NR4AI & nuclear receptor subfamily 4 , group $A$, member I & -3.7 & -3.78 & \\
\hline NM 006198 & PCP4 & Purkinje cell protein 4 & 4.85 & 8.23 & \\
\hline Al934473 & PIK3RI & phosphoinositide-3-kinase, regulatory subunit, polypeptide I (p85 alpha) & 3.01 & 2.21 & \\
\hline BC002665 & PLPI & proteolipid protein I (Pelizaeus-Merzbacher disease, spastic paraplegia 2, uncomplicated) & 4.75 & 12.1 & \\
\hline BC005939 & PTGDS & prostaglandin D2 synthase 2 I kDa (brain) & -2 & -3.47 & -2 \\
\hline D86096 & PTGER3 & prostaglandin E receptor 3 (subtype EP3) & & -4.2 & -2.8 \\
\hline NM 002937 & RNASE4 & ribonuclease, RNase A family, 4 & -2 & -3.38 & \\
\hline U8928I & $\mathrm{RODH}$ & 3-hydroxysteroid epimerase & 1.93 & 3.34 & \\
\hline NM 000602 & SERPINEI & serine (or cysteine) proteinase inhibitor, clade $\mathrm{E}$, member I & -4.4 & -4.09 & \\
\hline$\overline{B G 528420}$ & $\mathrm{SOX} 4$ & SRY (sex determining region Y)-box 4 & 3.98 & 2.81 & \\
\hline NM 003242 & TGFBR2 & transforming growth factor, beta receptor II & -1.8 & -2.02 & \\
\hline NM 021992 & TMSNB & thymosin, beta, identified in neuroblastoma cells & 1.59 & 5.51 & \\
\hline NM 007II6 & TNXB & tenascin $X B$ & -2.2 & -6.28 & \\
\hline NM 003294 & TPSB2 & tryptase beta 2 & -4.1 & -24.3 & \\
\hline AF349719 & TRO & trophinin & 1.74 & 3.3 & \\
\hline NM 00107I & TYMS & thymidylate synthetase & 2.1 & 9.12 & 3.3 \\
\hline
\end{tabular}

a Genbank or RefSeq accession number.

b Gene symbol or description were obtained from the BioConductor Project.

c Fold change of gene expression in uterine fibroids vs myometrium. H, T and W represent studies by Hoffman et al. [I8], Tsibris et al. [14] and

Wang et al. [17] respectively.

harbors a potential estrogen-responsive element (ERE) [36], was reported [37] to be an early responsive gene in the ovarectomized rat uterus to estrogen treatment. Insulin-like growth factor II (IGF2) was regulated in the estrogen-treated rat uterus (Table 3), but had previously been reported to be estrogen non-responsive. Rather, IGF-1 was found to be regulated by estrogen in human uterine fibroids [38], rhesus monkey myometrium [39] and rat uterus

[40].

In summary, by integrating multiple independent DNA microarray studies of differentially expressed genes in human uterine fibroids a group of thirty-eight genes were identified as consistently changed in the tumor versus surrounding normal myometrium. By ortholog gene analysis we identified a subset of these genes that were estrogenregulated in the rat array study. Six of the twelve ortholog genes have previously been described to be regulated by estrogen while the remaining genes have yet to be independently verified as estrogen-responsive.

\section{Discussion}

DNA microarray technology provides us with a great opportunity for looking at molecular mechanisms of disease development on a whole genome scale. While a few public databases have been built to facilitate data sharing 
Table 3: Human and rat orthologous genes differentially expressed in human uterine fibroids and E2-responsive in the rat uterus.

\begin{tabular}{|c|c|c|c|c|c|c|c|c|c|}
\hline \multirow[t]{2}{*}{ Gene } & \multirow[t]{2}{*}{ Symbol } & \multicolumn{3}{|c|}{ Uterine fibroids } & \multicolumn{2}{|c|}{ I-Day } & \multicolumn{2}{|c|}{ 5-Week } & \multirow[t]{2}{*}{ Previous reports on E2 regulation } \\
\hline & & $\mathbf{H}^{\mathrm{a}}$ & $\mathbf{T}^{\mathbf{a}}$ & $\mathbf{W a}^{\mathbf{a}}$ & ovx & E2 & ovx & E2 & \\
\hline prostaglandin E receptor 3 (subtype EP3) & PTGER3 & & -4.2 & -2.8 & 1.8 & -1.8 & 1.6 & -1.7 & None \\
\hline transforming growth factor, beta receptor II $(70 / 80 \mathrm{kDa})$ & TGFBR2 & -1.8 & -2.0 & & 3.3 & -3.2 & 5.4 & -15.6 & None \\
\hline Purkinje cell protein 4 & PCP4 & 4.9 & 8.2 & & NS & NS & -1.4 & 2.4 & None \\
\hline calcitonin receptor-like receptor & CALCRL & -2.1 & & -1.7 & 1.9 & -1.7 & 1.2 & -1.3 & [35] [34] \\
\hline aldehyde dehydrogenase I family, member AI & ALDHIAI & -3.5 & -8.0 & -3.8 & 7.7 & -9.0 & 4.5 & -4.4 & [28] [29] \\
\hline annexin $\mathrm{Al}$ & ANXAI & -4.1 & -4.3 & & -1.4 & 1.6 & NS & NS & [33] \\
\hline cellular retinoic acid binding protein 2 & CRABP2 & 3.1 & 5.1 & 2.6 & -23.1 & 37.6 & NS & NS & {$[28][29]$} \\
\hline prostaglandin D2 synthase 2 I kDa (brain) & L-PTGDS & -2.0 & -3.5 & -2.1 & 2.0 & -2.3 & 1.8 & -2.0 & {$[30,31][32]$} \\
\hline nuclear receptor subfamily 4 , group $A$, member I & NR4AI & -3.7 & -3.8 & & NS & NS & -1.8 & 5.4 & [37] [64] \\
\hline proteolipid protein I & PLPI & 4.8 & 12.1 & & 1.3 & -1.5 & 1.3 & -1.3 & None \\
\hline ribonuclease, RNase A family, 4 & RNASE4 & -2.0 & -3.4 & & NS & NS & 3.5 & -4.3 & None \\
\hline insulin-like growth factor 2 (somatomedin A) & IGF2 & & 16.8 & 2.6 & NS & NS & 2.2 & -1.6 & Contradictory to [38] [40] [39] \\
\hline
\end{tabular}

a Abbreviations: $\mathrm{H}$ for Hoffman et al study [18], T for Tsibris [14], and W for Wang et al. [17], ovx = ovariectomized rats, E2 = I7 $\beta$ - estradiol, and NS $=$ not statistically significant at $\alpha=0.05$.

$[20,41,42]$, it still remains a great challenge to integrate the data, particularly data generated from different organisms, in order to generate testable hypotheses. In the present work we integrated multiple microarray data sets generated by independent research groups from two different species using ortholog gene analysis to try to discover molecular clues to estrogen-dependent growth of human uterine fibroids. While this in silico analysis suggests pathways and individual gene product involvement in the regulation of fibroid tumor growth by estrogenic signaling, the authors recognize the need for experimental follow-up to prove these associations.

Thirty-eight human genes (Table 2) were identified in common from three independent studies showing differential expression between uterine fibroids and normal myometrium. Of these, twelve human and rat orthologous genes (Table 3 ) were shown to be estrogen-regulated in the rat uterus. Since they are human and rat orthologs, we inferred that they should share similar expression regulation and biological functions in both species. These genes provide important clues to understand estrogendependent growth of human uterine fibroids.

Prostaglandin E2 receptor subtype 3 (PTGER3 or EP3) is a G-protein-coupled receptor activated by prostaglandin E2 that was down regulated in uterine fibroids. Alternative splicing generates three isoforms: EP3 alpha, EP3 beta and EP3 gamma, which differ in the putative cytoplasmic carboxy-terminal tail. It was demonstrated that while EP3 gamma is coupled to both stimulation and inhibition of adenylate cyclase, EP3 alpha and beta are exclusively coupled to inhibition of adenylate cyclase [43]. Shoji et al. [44] demonstrated that EP3 plays an important role in suppression of cell growth and its down-regulation enhances colon carcinogenesis at a later stage. Transform-

\section{$>200$ kbintergenic region}

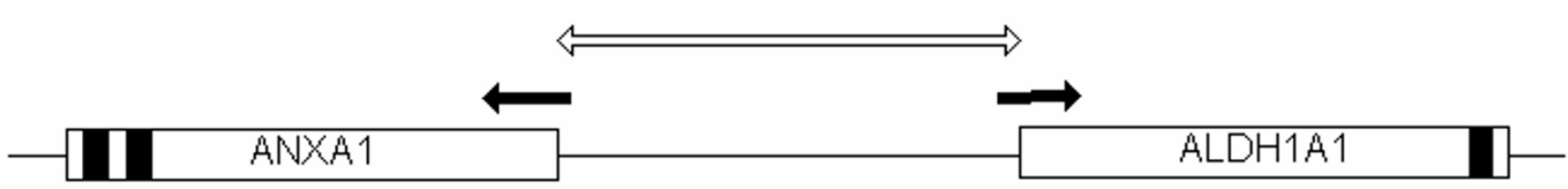

\section{Figure 3}

Conserved genomic structure of ALDHIAI and ANXAI genes among rat, mouse and human. Both genes are located on the same chromosome with head-to-head configuration. The configuration is conserved among three organisms. Filled arrows indicate transcription direction. Filled black bars are target sequences from which Affymetrix probes were derived. Over $200 \mathrm{~kb}$ of intergenic sequence is indicated by an empty arrow. 
ing growth factor-beta (TGF- $\beta$ ) is a potent inhibitor of normal epithelial cell proliferation and is increasingly implicated in fibroid growth. Many tumor cell lines do not respond to the inhibitory effects of TGF- $\beta$ due to a reduction or absence of the type II receptor (TGF- $\beta$ R2) [45]. The down-regulation of TGF- $\beta$ R2 in uterine fibroids is consistent with this finding. The PCP4 gene encoding PEP-19 is a calmodulin-regulatory protein found abundantly within neurons that was found to be increased in uterine fibroids. A study in PC12 cells [46] demonstrated that PEP-19 could inhibit apoptosis in the cells, suggesting that its up-regulation in human uterine fibroids may be similar. Thus, estrogen may promote cell survival and tumor growth by increasing expression of the anti-apoptotic PCP4 gene and by suppressing the expression of growth inhibitory receptors PTGER3 and TGF- $\beta$ R2.

The calcitonin receptor-like receptor (CALCRL or CRLR), a G-protein coupled receptor, acts as a receptor for adrenomedullin (ADM) or calcitonin gene related peptide (CGRP) depending on which receptor activity modifying protein (RAMP) it partners with [47]. Using a rat uterine fibroid-derived cell line (ELT3), Thota and Yallampalli [34] demonstrated that expression of CALCRL and RAMP1 increased with progesterone and decreased with estrogen, consistent with what Helvering et al found in the array work (Table 3). Down-regulation of CALCRL expression in the tumor and in response to estrogen may implicate two important aspects of the tumor growth, that is, cell proliferation and angiogenesis.

L-PGDS has dual molecular functions. It catalyzes the conversion of prostaglandin $\mathrm{H} 2$ ( $\mathrm{PGH} 2$ ) to prostaglandin D2 (PGD2) inside the cell and binds to small non-substrate lipophilic molecules including retinal, retinoic acid and thyroid hormone and serve as a transporter for these molecules once secreted [48]. ANXA1 is a calciumdependent phospholipid binding protein and belongs to the annexin family. It was originally identified as a protein that apparently modulated the release of arachidonic acid from cells [49]. Recent data have shown that ANXA1 may specifically target cytosolic phospholipase A2 (PLA2) by both direct enzyme inhibition and suppression of cytokine-induced activation of the enzyme [50]. CRABP2 is a member of a large family of small proteins that specifically bind lipophilic compounds such as fatty acids and retinoids [28]. Recent work has suggested that CRABP2 may have a role in the movement of retinoic acid (RA) to the RA receptors (RARs), thereby enhancing the action of RA in the cells in which it is expressed. ALDH1A1 belongs to the aldehyde dehydrogenase family and is a terminal enzyme of the pathway catalyzing conversion of retinal to RA [51]. NR4A1 (encoded by Nur77 in mouse, NGFI-B in rat, and TR3 in human) is an immediate-early responsive orphan nuclear receptor whose expression is rapidly induced by a variety of extracellular stimuli including estrogen as evidenced here (Table 3). Using Northern blot RNA analysis Cicatiello et al [37] reported that NR4A1 was transiently activated in the uterus (up to 20-fold) within 30-120 min after treatment of adult ovariectomized rats with estrogen.

Five of the ortholog genes (ANXA1, L-PGDS, ALDH1A1, CRABP2 and NR4A1) were found to be linked via their physiological functions following pathway analysis as summarized in Fig. 4. Estrogen may antagonize PPAR $\gamma$ mediated signaling first by up-regulating ANXA1 gene expression, thereby inhibiting phospholipase A2 activity and reducing arachinoic acid production, a common substrate for prostaglandin synthesis. Secondly, estrogen may antagonize PPAR $\gamma$ mediated signaling by down-regulating L-PGDS gene expression, which reduces conversion of PGH2 to PGD2 thus decreasing synthesis of PGJ2, an endogenous ligand for PPAR $\gamma$ activation. Recent work may provide clues to understand the physiological significance of these molecular events in the context of estrogen-dependent fibroid growth. Houston et al. [11] demonstrated that PPAR $\gamma$ upon its activation by its endogenous ligand PGJ2, suppressed estrogen-dependent fibroid growth. The authors hypothesized that PPAR $\gamma$ achieved its antagonistic effect by competitively binding to estrogen-responsive elements on promoters of genes which may be required for estrogen-dependent tumor growth. Yuan et al [52] showed that PPAR $\gamma$ activation by pioglitazone greatly retarded the progression of rat hepatic fibrosis. Shimada et al [53] reported that PPAR $\gamma$ ligands, including PGJ2, induced apoptosis in colon cancer cells and the same group [54] demonstrated that PPAR $\gamma$ plays an important role in the regulation of cell growth and cell death in gastric epithelial cells. It was reported [12] that human uterine fibroids expressed significantly higher levels of PPAR $\gamma$, retinoid $\times$ receptor $\alpha$ and all-trans retinoic acid than myometrium. Thus we hypothesize that estrogen helps tumor cell survival and growth by interfering with PPAR $\gamma$-mediated apoptosis at multiple steps in the biosynthesis of its ligand.

Retinoic acid (RA) has been established as a biologically active form of vitamin A (retinol). Fig 4 shows that biosynthesis of RA occurs by two sequential irreversible oxidations, first producing retinal from retinol by retinal dehydrogenases (RolDHs). The retinal is then oxidized to RA by retinal dehydrogenases (RalDHs) of the alcohol dehydrogenase $(\mathrm{ADH})$ family 1 (also known as ALDH1A1-3). Tsibris et al [12] demonstrated that estrogen induced formation of abdominal fibroids in the guinea pig, and RA in combination with estrogen was required to specifically induce formation of fibroids in the uterus. Estrogen-induced guinea pig uterine fibroids are similar to the human fibroids, in that they also expressed 


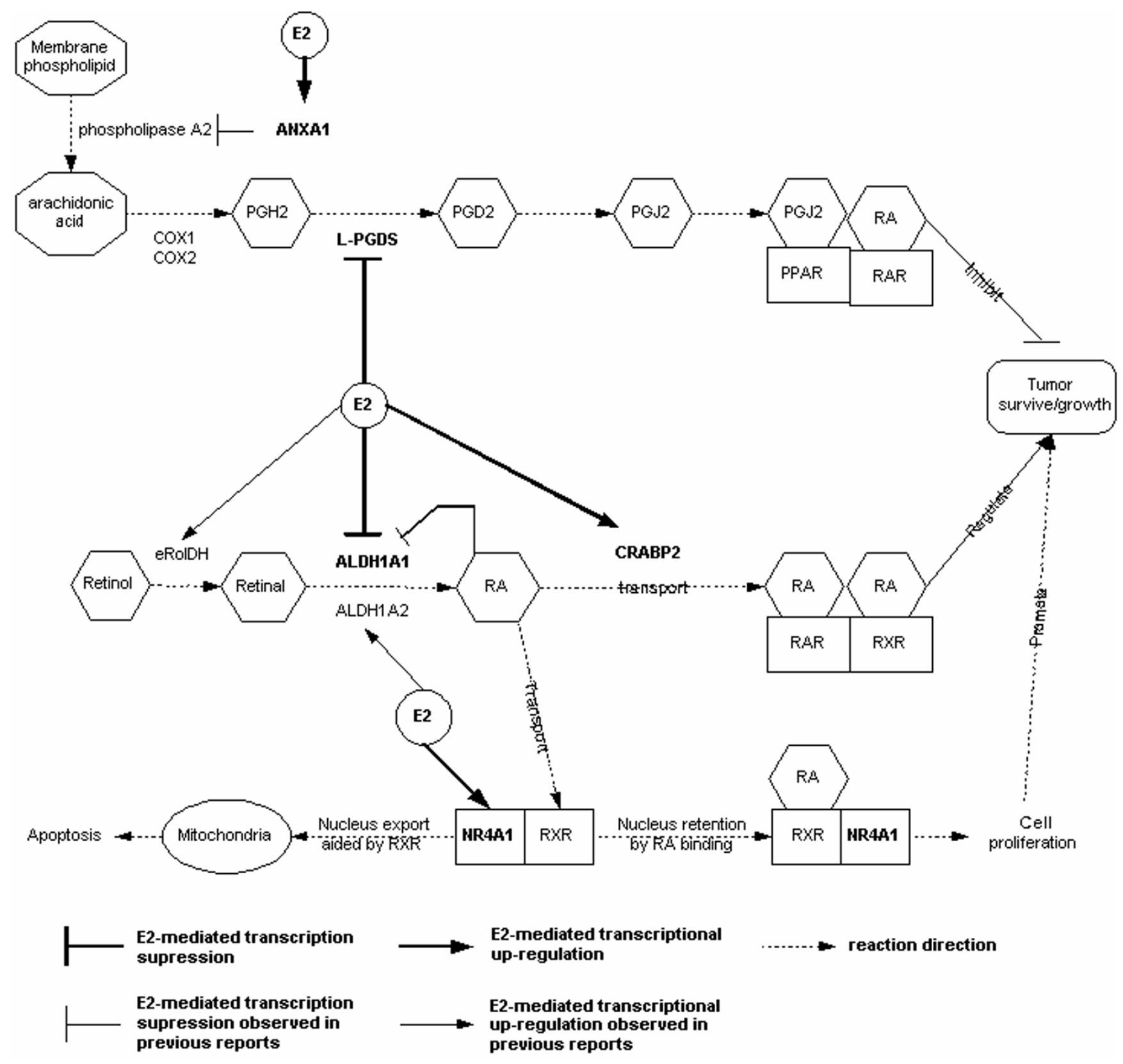

Figure 4

Multiple estrogen-regulated steps in the metabolisms of prostaglandin $\mathrm{J} 2$ and retinoic acid are implicated in estrogen-dependent growth of human uterine fibroids. Prostaglandin synthesis pathway was taken from the KEGG pathway database and simplified. Retinoic acid metabolic pathway was compiled based on previous work [5I], [29] and [55]. E2 stands for $17 \beta$-estradiol, PGH2 for prostaglandin H2, PGD2 for prostaglandin D2, PGJ2 for prostaglandin J2, RA for retinoic acid, RAR for RA receptor, RXR for retinoid $\times$ receptor, PPAR for peroxisome proliferator-activated receptor. Five human and rat ortholog and estrogen-regulated genes (NR4AI, ANXAI, L-PGDS, ALDHIAI and CRABP2) are in bold font. NR4AI is nuclear receptor subfamily 4, group A, member I, which is also called NGFI-B (neuronal growth factor-induced clone B) in rat, Nur77 in mouse and TR3 in human. Its roles in cell proliferation and apoptosis summarized in the figure were largely taken from Cao et al [36] and references therein. ANXAI stands for annexin AI, L-PGDS for lipocalin-type prostaglandin D2 synthase, ALDHIAI and ALDHIA2 for aldehyde dehydrogenase I family, member $\mathrm{A} I$ and member $\mathrm{A} 2$ respectively, CRABP2 for cellular retinoic acid binding protein 2, COXI and COX2 for cyclooxygenase I and 2, eRoIDH for epithelial retinal dehydrogenase [63]. 
increased levels of PPAR $\gamma$, RXR- $\alpha$ and all-trans retinoic acid. Our integrated analysis of expression data collected by independent studies revealed that expression of two genes, ALDH1A1 and CRABP2 for RA synthesis or mobilization was differentially expressed in human uterine fibroids and regulated by estrogen in the rat uterus. Previous studies in rodents have suggested that estrogen directly induces uterine RA synthesis by increasing expression of epithelial retinal dehydrogenase $(e$ RolDH) and ALDH1A2 (reviewed in [29]). Reduction of ALDH1A1 expression (Table 3) may not directly result from estrogen regulation but rather be due to feedback inhibition by RA [55]. RA acts on tumor growth by binding and regulating the tumor cell heterodimeric receptors RAR and RXR. RXR may also exert its effects on tumor cell survival and growth by partnering with PPAR $\gamma$ and/or NR4A1. NR4A1 was originally recognized for its role in cell proliferation and differentiation. It may confer its growth effects by transactivating target genes required for cell proliferation in nucleus [56]. On the other hand, it also acts on mitochondria (non-trans-activation activity) to induce apoptosis. It was demonstrated that its nuclear export and initiation of NR4A1-dependent apoptosis depends on the nuclear exporting signal (NES) residing on its binding partner RXR and is suppressed by RA [36]. Thus, increased expression of NR4A1 and elevated levels of RA in response to estrogen could promote cell proliferation and suppress pro-apoptosis activity. Proteolipid and DM20 encoded by the PLP1 gene through alternative splicing are major structural components of central nervous system myelin. It has been well established that steroid hormones such as estrogen and progesterone regulate the expression of myelin proteins such as proteolipid protein (reviewed in [57]). However, what roles PLP1 may play in the development of human uterine fibroids needs further study. Similarly we have little knowledge of what functions that RNase A family, 4 (RNASE4) plays in the tumor growth. It is worthwhile to note that directions of expression changes of ANXA1, NR4A1 and PLP1 were opposite from that of the estrogen treated rat uterus.

Human genetics studies have shown that $40-50 \%$ of human uterine fibroids display karyotypically detectable chromosomal abnormalities [2]. Twenty percent of the abnormality is the characteristic translocation $\mathrm{t}(12: 14)$ $[58,59]$. The twelve estrogen-regulated genes identified in the present study did not map to this translocation. The most prominent predisposition genes involved in human uterine fibroids, HGMI(c) and HMGI (Y), account for nearly $50 \%$ of the genetic variation in human uterine fibroids [59]. Dysregulation of these genes through chromosomal translation is a major event in uterine fibroid formation. Rearrangement of $\operatorname{HMGI}(\mathrm{C})$ and $\operatorname{HMGI}(\mathrm{Y})$ is also a very frequent event in many mesenchymal tumors, suggesting a critical role of the HMGI complex in tumori- genesis. The two key estrogen regulated pathways (e.g. RA and PPAR $\gamma$ ) identified in the present study were both reported to be interacting with the HMG complex. For example, orchestrated action from PPAR $\gamma, \operatorname{HMGI}(\mathrm{C})$, and other transcription factors is required in directing adipocyte differentiation [60]. Altered activity of these transcription factors could lead to biased differentiation of adipocytes or even adipocyte hyperplasia. Moreover, the retinoic acid pathway could regulate or be regulated by HMGI(C) during neuroblastoma tumorigenesis. Both HMGI(C), and HMGI(Y) are expressed in neuroblastoma cell lines and tumors and they are regulated by RA both at the RNA and protein levels, and can affect the responsiveness of these cells to RA [61,62]. A causal link has been proposed between HMGI(C) expression and RA induced growth arrest during tumorigenesis. Given the pivotal roles of the HMG complex in the fibroids and their interaction with PPAR $\gamma$ and RA pathways in controlling adipocyte growth and tumorigenesis of neuroblastoma, we speculate that estrogen may regulate fibroid growth through the PPAR $\gamma$ and RA pathways and their interaction with the HMGI(C) and HGMI(Y) complex. However, the direct link between HMG complex with RA and/or PPAR $\gamma$ in human uterine fibroids needs to be established experimentally, and is an area for future investigation.

\section{Conclusion}

In conclusion, integration of multiple DNA microarray studies through ortholog gene analysis identified twelve uterine fibroid disease genes that may respond to estrogen in the fibroid. Functional and pathway analyses suggested multiple molecular mechanisms for estrogen-dependent growth of human uterine fibroids: enhanced tumor cell survival by increased expression of PCP4 and decreased expression of TGF- $\beta$ R2 and PTGER3 and the complex interplay among five distinct nuclear receptors (ER, RAR, RXR, NR4A1 and PPAR $\gamma$ ) that may enhance tumor cell survival and growth. Fully understanding the exact molecular interactions among these genes requires further study to validate their role in uterine fibroids. This work provides direction for studies which could influence the future direction of therapeutic intervention for the disease.

\section{Competing interests}

The author(s) declare that they have no competing interests.

\section{Authors' contributions}

TW, AGG, CS, JS and MNC participated in collecting, analyzing and interpreting array data. TW drafted the manuscript. HQ performed statistical analysis of the array data published by Hoffman et al (2003). LMH, NHK, HUB and JEO designed the rat uterus array study. JEO supervised 
the overall work. All authors read and approved the final manuscript.

\section{Acknowledgements}

We thank Dr. Rachelle Galvin for her thoughtful comments. We wish to acknowledge funding from Lilly Research Laboratories.

\section{References}

I. Stewart EA: Uterine fibroids. Lancet 200I, 357(9252):293-298

2. Flake GP, Andersen J, Dixon D: Etiology and pathogenesis of uterine leiomyomas: a review. Environ Health Perspect 2003, I I I(8): I037-1054.

3. Gambone JC, Reiter RC, Lench JB, Moore JG: The impact of a quality assurance process on the frequency and confirmation rate of hysterectomy. Am J Obstet Gynecol 1990, 163(2):545-550.

4. Friedman AJ, Harrison-Atlas D, Barbieri RL, Benacerraf B, Gleason R, Schiff I: A randomized, placebo-controlled, double-blind study evaluating the efficacy of leuprolide acetate depot in the treatment of uterine leiomyomata. Fertil Steril 1989, 5I(2):25I-256.

5. Folkerd EJ, Newton CJ, Davidson K, Anderson MC, James VH: Aromatase activity in uterine leiomyomata. J Steroid Biochem I984, 20(5): I I 95- I 200.

6. Green S, Walter P, Kumar V, Krust A, Bornert JM, Argos P, Chambon $P$ : Human oestrogen receptor cDNA: sequence, expression and homology to v-erb-A. Nature 1986, 320(6058): I34-139.

7. Kumar V, Green S, Stack G, Berry M, Jin JR, Chambon P: Functional domains of the human estrogen receptor. Cell 1987, 5 I (6): $941-951$.

8. Mitchell DC, Ing NH: Estradiol stabilizes estrogen receptor messenger ribonucleic acid in sheep endometrium via discrete sequence elements in its 3 '-untranslated region. Mol Endocrinol 2003, I7(4):562-574.

9. Hayashi S, Sakamoto T, Inoue A, Yoshida N, Omoto Y, Yamaguchi Y: Estrogen and growth factor signaling pathway: basic approaches for clinical application. I Steroid Biochem Mol Biol 2003, 86(3-5):433-442.

10. Fukuhara K, Kariya M, Kita M, Shime H, Kanamori T, Kosaka C, Orii A, Fujita J, Fujii S: Secreted frizzled related protein I is overexpressed in uterine leiomyomas, associated with a high estrogenic environment and unrelated to proliferative activity. J Clin Endocrinol Metab 2002, 87(4): I729-1736.

11. Houston KD, Copland JA, Broaddus RR, Gottardis MM, Fischer SM, Walker CL: Inhibition of proliferation and estrogen receptor signaling by peroxisome proliferator-activated receptor gamma ligands in uterine leiomyoma. Cancer Res 2003, 63(6): $1221-1227$

12. Tsibris JC, Porter KB, Jazayeri A, Tzimas G, Nau H, Huang $H$, Kuparadze K, Porter GW, O'Brien WF, Spellacy WN: Human uterine leiomyomata express higher levels of peroxisome proliferator-activated receptor gamma, retinoid $X$ receptor alpha, and all-trans retinoic acid than myometrium. Cancer Res 1999, 59(22):5737-5744.

13. Shalon D, Smith SJ, Brown PO: A DNA microarray system for analyzing complex DNA samples using two-color fluorescent probe hybridization. Genome Res 1996, 6(7):639-645.

14. Tsibris JC, Segars J, Coppola D, Mane S, Wilbanks GD, O'Brien WF, Spellacy WN: Insights from gene arrays on the development and growth regulation of uterine leiomyomata. Fertil Steril 2002, 78(I):||4-|2|.

15. Helvering LM, Adrian MD, Geiser AG, Estrem ST, Wei T, Huang S, Chen P, Dow ER, Calley JN, Dodge JA, Grese TA, Jones SA, Halladay $D L$, Miles RR, Onyia JE, Ma YL, Sato M, Bryant HU: Differential effects of estrogen and raloxifene on messenger RNA and matrix metalloproteinase 2 activity in the rat uterus. Biol Reprod 2005, 72(4):830-84I.

16. Jimenez JL, Mitchell MP, Sgouros JG: Microarray analysis of orthologous genes: conservation of the translational machinery across species at the sequence and expression level. Genome Biol 2003, 4(I):R4.

17. Wang H, Mahadevappa M, Yamamoto K, Wen $Y$, Chen B, Warrington JA, Polan ML: Distinctive proliferative phase differences in gene expression in human myometrium and leiomyomata. Fertil Steril 2003, 80(2):266-276.
18. Hoffman PJ, Milliken DB, Gregg LC, Davis RR, Gregg JP: Molecular characterization of uterine fibroids and its implication for underlying mechanisms of pathogenesis. Fertil Steril 2004, 82(3):639-649.

19. Benjamini $Y$, Hochberg: Controlling the false discovery rate:a practical and powerful approach to multiple testing. The Journal of Royal Statistical Society 1995, 57(I):289-300.

20. Edgar R, Domrachev M, Lash AE: Gene Expression Omnibus: NCBI gene expression and hybridization array data repository. Nucleic Acids Res 2002, 30(1):207-210.

21. NetAffx [http://www.affymetrix.com/analysis/index.affx].

22. Wheeler DL, Church DM, Federhen S, Lash AE, Madden TL, Pontius JU, Schuler GD, Schriml LM, Sequeira E, Tatusova TA, Wagner L: Database resources of the National Center for Biotechnology. Nucleic Acids Res 2003, 3 I ( I):28-33.

23. Lee Y, Sultana R, Pertea G, Cho J, Karamycheva S, Tsai J, Parvizi B, Cheung F, Antonescu V, White J, Holt I, Liang F, Quackenbush J: Cross-referencing eukaryotic genomes: TIGR Orthologous Gene Alignments (TOGA). Genome Res 2002, I 2(3):493-502.

24. Kent W]: BLAT--the BLAST-like alignment tool. Genome Res 2002, I 2(4):656-664.

25. Curwen V, Eyras E, Andrews TD, Clarke L, Mongin E, Searle SM, Clamp M: The Ensembl automatic gene annotation system. Genome Res 2004, I 4(5):942-950.

26. Al-Shahrour F, Diaz-Uriarte R, Dopazo J: FatiGO: a web tool for finding significant associations of Gene Ontology terms with groups of genes. Bioinformatics 2004, 20(4):578-580.

27. UCSC Genome Bioinformatics [http://genome.ucsc.edu/].

28. Li XH, Ong DE: Cellular retinoic acid-binding protein II gene expression is directly induced by estrogen, but not retinoic acid, in rat uterus. J Biol Chem 2003, 278(37):35819-35825.

29. $\mathrm{Li} \mathrm{XH}$, Kakkad B, Ong DE: Estrogen directly induces expression of retinoic acid biosynthetic enzymes, compartmentalized between the epithelium and underlying stromal cells in rat uterus. Endocrinology 2004, I 45( I 0):4756-4762.

30. Mong JA, Devidze N, Frail DE, O'Connor LT, Samuel M, Choleris E, Ogawa S, Pfaff DW: Estradiol differentially regulates lipocalintype prostaglandin $D$ synthase transcript levels in the rodent brain: Evidence from high-density oligonucleotide arrays and in situ hybridization. Proc Natl Acad Sci U S A 2003, 100(I):318-323.

31. Mong JA, Devidze N, Goodwillie A, Pfaff DW: Reduction of lipocalin-type prostaglandin $D$ synthase in the preoptic area of female mice mimics estradiol effects on arousal and sex behavior. Proc Natl Acad Sci U S A 2003, I00(25): I5206-I52II.

32. Otsuki M, Gao H, Dahlman-Wright K, Ohlsson C, Eguchi N, Urade $Y$, Gustafsson JA: Specific regulation of lipocalin-type prostaglandin $D$ synthase in mouse heart by estrogen receptor beta. Mol Endocrinol 2003, 17(9): 1844-1855.

33. Castro-Caldas M, Duarte CB, Carvalho AR, Lopes MC: I7betaestradiol promotes the synthesis and the secretion of annexin $I$ in the CCRF-CEM human cell line. Mediators Inflamm 200I, I 0(5):245-25I.

34. Thota C, Yallampalli C: Progesterone upregulates calcitonin gene-related peptide and adrenomedullin receptor components and cyclic adenosine 3'5'-monophosphate generation in Eker rat uterine smooth muscle cell line. Biol Reprod 2005, 72(2):416-422.

35. Dong YL, Vegiraju S, Chauhan M, Yallampalli C: Expression of calcitonin gene-related peptide receptor components, calcitonin receptor-like receptor and receptor activity modifying protein $\mathrm{I}$, in the rat placenta during pregnancy and their cellular localization. Mol Hum Reprod 2003, 9(8):48I-490.

36. Cao X, Liu W, Lin F, Li H, Kolluri SK, Lin B, Han YH, Dawson MI, Zhang XK: Retinoid $X$ receptor regulates Nur77/TR3-dependent apoptosis [corrected] by modulating its nuclear export and mitochondrial targeting. Mol Cell Biol 2004, 24(22):9705-9725.

37. Cicatiello L, Sica V, Bresciani F, Weisz A: Identification of a specific pattern of "immediate-early" gene activation induced by estrogen during mitogenic stimulation of rat uterine cells. Receptor 1993, 3(1): 17-30.

38. Giudice LC, Irwin JC, Dsupin BA, Pannier EM, Jin IH, Vu TH, Hoffman AR: Insulin-like growth factor (IGF), IGF binding protein (IGFBP), and IGF receptor gene expression and IGFBP syn- 
thesis in human uterine leiomyomata. Hum Reprod 1993, 8(II):1796-1806.

39. Adesanya OO, Zhou J, Bondy CA: Sex steroid regulation of insulin-like growth factor system gene expression and proliferation in primate myometrium. J Clin Endocrinol Metab 1996, 8I(5):1967-I 974.

40. Norstedt G, Levinovitz A, Eriksson H: Regulation of uterine insulin-like growth factor I mRNA and insulin-like growth factor II mRNA by estrogen in the rat. Acta Endocrinol (Copenh) 1989, I 20(4):466-472.

41. Kawamoto S, Matsumoto Y, Mizuno K, Okubo K, Matsubara K: Expression profiles of active genes in human and mouse livers. Gene 1996, I74(1):151-158.

42. Rocca-Serra P, Brazma A, Parkinson H, Sarkans U, Shojatalab M, Contrino S, Vilo J, Abeygunawardena N, Mukherjee G, Holloway E, Kapushesky M, Kemmeren P, Lara GG, Oezcimen A, Sansone SA: ArrayExpress: a public database of gene expression data at EBI. C R Biol 2003, 326(I0-I I): 1075- 1078.

43. Irie A, Sugimoto Y, Namba T, Harazono A, Honda A, Watabe A, Negishi M, Narumiya S, Ichikawa A: Third isoform of the prostaglandin-E-receptor EP3 subtype with different C-terminal tail coupling to both stimulation and inhibition of adenylate cyclase. Eur J Biochem 1993, 217(I):313-318.

44. Shoji Y, Takahashi M, Kitamura T, Watanabe K, Kawamori T, Maruyama T, Sugimoto Y, Negishi M, Narumiya S, Sugimura T, Wakabayashi K: Downregulation of prostaglandin $E$ receptor subtype EP3 during colon cancer development. Gut 2004, 53(8): $|15|-|| 58$.

45. Barlow J, Yandell D, Weaver D, Casey T, Plaut K: Higher stromal expression of transforming growth factor-beta type II receptors is associated with poorer prognosis breast tumors. Breast Cancer Res Treat 2003, 79(2): I49-159.

46. Erhardt JA, Legos JJ, Johanson RA, Slemmon JR, Wang X: Expression of PEP-19 inhibits apoptosis in PCI2 cells. Neuroreport 2000, I I(I7):3719-3723.

47. Beltowski J, Jamroz A: Adrenomedullin--what do we know 10 years since its discovery? Pol J Pharmacol 2004, 56(I):5-27.

48. Urade $Y$, Hayaishi $O$ : Biochemical, structural, genetic, physiological, and pathophysiological features of lipocalin-type prostaglandin D synthase. Biochim Biophys Acta 2000, I 482(I2):259-27I.

49. Flower RJ, Rothwell NJ: Lipocortin-I: cellular mechanisms and clinical relevance. Trends Pharmacol Sci 1994, I5(3):7I-76.

50. Parente L, Solito E: Annexin I: more than an anti-phospholipase protein. Inflamm Res 2004, 53(4): I25-I32.

5I. Duester G: Families of retinoid dehydrogenases regulating vitamin A function: production of visual pigment and retinoic acid. Eur J Biochem 2000, 267( I 4):43 I5-4324.

52. Yuan GJ, Zhang ML, Gong Z]: Effects of PPARg agonist pioglitazone on rat hepatic fibrosis. World J Gastroenterol 2004, I0(7): |047-| $05 \mid$.

53. Shimada T, Kojima K, Yoshiura K, Hiraishi H, Terano A: Characteristics of the peroxisome proliferator activated receptor gamma (PPARgamma) ligand induced apoptosis in colon cancer cells. Gut 2002, 50(5):658-664.

54. Kojima K, Shimada T, Mitobe Y, Yoshiura K, Hiraishi H, Terano A: Effect of PPARgamma ligands on the viability of gastric epithelial cells. Aliment Pharmacol Ther 2002, 16 Suppl 2:67-73.

55. Elizondo G, Corchero J, Sterneck E, Gonzalez FJ: Feedback inhibition of the retinaldehyde dehydrogenase gene ALDHI by retinoic acid through retinoic acid receptor alpha and CCAAT/enhancer-binding protein beta. J Biol Chem 2000, 275(50):39747-39753.

56. Kolluri SK, Bruey-Sedano N, Cao X, Lin B, Lin F, Han YH, Dawson MI, Zhang XK: Mitogenic effect of orphan receptor TR3 and its regulation by MEKKI in lung cancer cells. Mol Cell Biol 2003, 23(23):865I-8667.

57. Chan JR, Rodriguez-Waitkus PM, Ng BK, Liang P, Glaser M: Progesterone synthesized by Schwann cells during myelin formation regulates neuronal gene expression. Mol Biol Cell 2000, I I(7):2283-2295.

58. Ligon AH, Morton CC: Genetics of uterine leiomyomata. Genes Chromosomes Cancer 2000, 28(3):235-245.

59. Ligon AH, Morton CC: Leiomyomata: heritability and cytogenetic studies. Hum Reprod Update 200I, 7(I):8-14.
60. Auwerx J, Martin G, Guerre-Millo M, Staels B: Transcription, adipocyte differentiation, and obesity. J Mol Med 1996, 74(7):347-352.

6I. Giannini G, Di Marcotullio L, Ristori E, Zani M, Crescenzi M, Scarpa S, Piaggio G, Vacca A, Peverali FA, Diana F, Screpanti I, Frati L, Gulino $A$ : $\mathrm{HMGI}(Y)$ and $\mathrm{HMGI}-\mathrm{C}$ genes are expressed in neuroblastoma cell lines and tumors and affect retinoic acid responsiveness. Cancer Res 1999, 59(10):2484-2492.

62. Giannini G, Kim CJ, Di Marcotullio L, Manfioletti G, Cardinali B, Cerignoli F, Ristori E, Zani M, Frati L, Screpanti I, Guilino A: Expression of the $\mathrm{HMGI}(Y)$ gene products in human neuroblastic tumours correlates with differentiation status. $\mathrm{Br} J$ Cancer 2000, 83 (II): 1503-1509.

63. Rexer BN, Ong DE: A novel short-chain alcohol dehydrogenase from rats with retinol dehydrogenase activity, cyclically expressed in uterine epithelium. Biol Reprod 2002, 67(5): $1555-1564$

64. Uemura H, Mizokami A, Chang C: Identification of a new enhancer in the promoter region of human TR3 orphan receptor gene. A member of steroid receptor superfamily. Biol Chem 1995, 270(10):5427-5433.

\section{Pre-publication history}

The pre-publication history for this paper can be accessed here:

http://www.biomedcentral.com/1472-6874/7/5/prepub

Publish with Biomed Central and every scientist can read your work free of charge

"BioMed Central will be the most significant development for disseminating the results of biomedical research in our lifetime. "

Sir Paul Nurse, Cancer Research UK

Your research papers will be:

- available free of charge to the entire biomedical community

- peer reviewed and published immediately upon acceptance

- cited in PubMed and archived on PubMed Central

- yours - you keep the copyright
BiolMedcentral 